\title{
SOBRE O CONCEITO DE ARTE E A FORMAÇÃO ESCOLAR NA EDUCAÇÃO DE JOVENS E ADULTOS
}

\author{
Gustavo Cunha de Araújo ${ }^{1}$ \\ Ana Arlinda de Oliveira ${ }^{2}$
}

\section{RESUMO}

O artigo tem por objetivo entender a formação escolar do estudante da Educação de Jovens e Adultos e compreender como são construídos alguns conceitos sobre a arte nessa modalidade educacional. Discutimos brevemente aspectos históricos do surgimento da EJA no Brasil e em Mato Grosso, na intenção de contextualizar historicamente o problema deste estudo, além de refletir as relações entre arte e sociedade, a qual é entendida como conhecimento humano, objeto estético e artístico, fruto do processo histórico e social da humanidade. É evidente nas falas dos alunos da EJA que a maioria deixou a escola devido à necessidade de trabalhar, ocasionando a evasão escolar, que é um grave problema para a educação brasileira. Além disso, os conteúdos de Arte na Educação de Jovens e Adultos devem contribuir para a preparação e maior inserção desses alunos no mercado de trabalho e, também, como participantes críticos e ativos na sociedade, ao compreenderem que o conhecimento é construído socialmente durante a aprendizagem em arte e no contato constante com as manifestações artísticas, tendo no professor e na escola importantes mediadores para esse processo.

Palavras-Chave: Ensino de Arte; Educação de Jovens e Adultos; Conceitos sobre a Arte; Formação Escolar.

\section{ABOUT THE CONCEPT OF ART AND TRAINING SCHOOL IN YOUNGSTERS AND ADULTS EDUCATION}

\begin{abstract}
The scientific paper aims to understand the training school of the student in Youngsters and Adults Education and understanding are built as his views on art in this modality. We discuss historical aspects of the emergence of youngsters and adults education in Brazil and Mato Grosso state, with the intention of contextualizing historically this research, in addition to reflections on relations between art and society, which is understood as human knowledge, aesthetic object and artistic, due to the social and historical process of humanity. It is evident in the speech of students in youngsters and adults education that most left school due to the necessity of working, leading to truancy, which is a serious problem for Brazilian education. In addition, the contents of arts in youngsters and adults education should contribute to the preparation and greater integration of these students into the labor market and also as critical and active participants in society, to understand that knowledge is socially constructed during learning in art and in constant contact with the artistic demonstrations, with the teacher and school important mediators in this process.
\end{abstract}

Keywords: Art Education; Youngsters and Adults Education; Concepts About Art; Training School. 


\section{Introdução}

O artigo tem por objetivo entender a formação escolar do estudante da Educação de Jovens e Adultos e compreender como são construídos alguns conceitos sobre a arte nessa modalidade educacional. Com efeito, discutimos aspectos históricos do surgimento da EJA no Brasil e em Mato Grosso, na intenção de contextualizar historicamente a problemática deste estudo, além de refletir as relações entre arte e sociedade, a qual é entendida como conhecimento humano, objeto estético e artístico, fruto do processo histórico e social da humanidade.

Esta pesquisa foi desenvolvida numa escola da rede pública de ensino localizada na cidade de Cuiabá, em Mato Grosso. A seleção dessa escola se justifica pelo fato de ser considerada referência na Educação de Jovens e Adultos nesse Estado. A pesquisa se fundamentou na epistemologia qualitativa, descritiva e interpretativa. Neste artigo ressaltamos algumas entrevistas gravadas e transcritas realizadas com os alunos da Educação de Jovens e Adultos, que fazem parte de resultados de um estudo desenvolvido no mestrado em educação.

$\mathrm{Na}$ primeira parte deste artigo são apresentados brevemente alguns aspectos históricos da Educação de Jovens e Adultos no Brasil e em Mato Grosso. Embora nossa intenção não seja aprofundar a discussão sobre a história da EJA na educação brasileira e mato-grossense, ressaltamos alguns momentos históricos que nos parecem ser significativos e pertinentes para o debate proposto neste texto. A segunda parte é caracterizada pelas reflexões sobre arte e sociedade, fundamentais para compreendermos alguns conceitos dos alunos jovens e adultos sobre a arte. No momento seguinte, são discutidas algumas funções sociais da arte na intenção de entender suas dimensões na Educação de Jovens e Adultos. Por fim, são apresentadas duas categorias importantes analisadas neste texto: os conceitos de arte de estudantes da EJA, e como ocorreu a formação escolar desses sujeitos.

Vale destacar que aprofundar e pesquisar o ensino de arte na Educação de Jovens e Adultos é uma forma de ampliar a produção de conhecimento no campo da pesquisa em educação, pois há escassez de pesquisas sobre essa temática na história da educação brasileira.

\section{Aspectos Históricos da EJA no Brasil e em Mato Grosso}

Segundo Paiva (2003) foi na época Colonial que se iniciou a educação de adultos no Brasil, por meio de ações educativas de missionários religiosos. Essas primeiras iniciativas surgiram concomitante à educação elementar com os jesuítas, que ensinavam não apenas as crianças, mas também seus pais. Mesmo a leitura e a escrita ainda serem precárias nesse momento histórico do Brasil, as primeiras escolas noturnas só vão surgir efetivamente no Império. Ainda segundo essa teórica, tal progresso serviu de incentivo para a disseminação de escolas voltadas para a educação de adultos no país, em diferentes províncias, inclusive em Mato Grosso, principalmente após a primeira guerra mundial.

No entanto, o Parecer CNE/CEB n. ${ }^{\circ}$ 11/2000 informa que a partir da Constituição Imperial de 1824 começou a ser esboçado uma legislação da EJA no país, pois foi neste contexto que foi instituído a instrução primária gratuita a todos, num momento em que a analfabetização e a baixa escolaridade assolava o país. Nesse período foi criado também o Decreto n. ${ }^{\circ} 7.247$ de abril de 1879 de Leôncio de Carvalho que previa a criação de cursos voltados para adultos analfabetos. 
No que se refere à escolarização de jovens e adultos em Mato Grosso, a implantação de uma modalidade de EJA nesse Estado se deu com a criação de cursos noturnos destinados "a uma classe de homens que vivem de seus trabalhos manuais, provavelmente pobres, que prestavam serviços na cidade" (SÁ; SOUZA, 2012, p.103). Segundo esses autores, a criação desses cursos não satisfez plenamente os objetivos propostos, que era alfabetizar esses estudantes.

Para Souza (2007), assim como em todo Brasil, a educação mato-grossense no período Republicano passou por relevantes mudanças, principalmente nos campos político, econômico e educacional. Segundo essa autora, a preocupação nesse período era voltada ao elevado número de analfabetos que crescia constantemente no país. Nesse momento houve novas tentativas de implantação de cursos noturnos voltados para a educação de jovens e adultos em Mato Grosso, pois o problema da analfabetização ainda era pertinente no país, ao atingir mais da metade da população (SÁ; SOUSA, 2012). Mesmo com poucos investimentos nesta modalidade de ensino nessa época, foram às instituições privadas e militares que, por meio das escolas regimentais, tiveram melhores iniciativas de investimento na EJA.

No decorrer dos anos 40, a situação educacional em Mato Grosso não era muito diferente do que ocorria no restante do país. Sobre esse aspecto, Souza (2007) traz uma importante reflexão:

O Estado de Mato Grosso, nos anos 40, apresentava uma dualidade conflitante no que se refere à educação. Por um lado, escolas que serviam a uma camada social mais elitizada e de outro, escolas destinadas às classes menos favorecidas. Esse quadro foi agravado pela Campanha "Marcha para o Oeste", que tinha como finalidade formar colônias agrícolas no sul de Mato Grosso, com os excedentes populacionais de brasileiros em situação de desemprego, oriundos de outras regiões do Brasil. Todo esse processo migratório aumentou a demanda de uma população não escolarizada, o que era preocupante para o Governo Getulista que proclamava ser através da escolarização da população a única maneira de eliminar os obstáculos para o desenvolvimento da nação (SOUZA, 2007, p.53).

Em adição a esse pensamento, Rezende (2008) descreve que os Centros de Estudos Supletivos (CES), Núcleo de Estudos Supletivos (NES), Núcleos de Educação Permanente (NEPs) e por meio de projetos como o Modular, todos nas décadas de 1970 a 1990, tiveram participação importante na construção da história da educação da EJA em Mato Grosso. Assim relata:

esses cursos foram criados para resolver o problema do déficit educacional do Brasil, e Mato Grosso adotou o seu primeiro curso CES em 1974 em sua capital, Cuiabá. A metodologia própria desses cursos fazia com que as pessoas que trabalhavam tivessem a chance de concluir o segundo grau. O ensino era personalizado e acompanhado de módulos instrucionais, que possibilitavam o estudo individualizado do aluno de acordo com a sua disponibilidade de tempo. A presença não era obrigatória e o atendimento era individual ou em grupo (REZENDE, 2008, p.52). 
Devido ao fato do Estado de Mato Grosso ter uma das maiores extensões territoriais do Brasil, pensamos que seja importante e necessário uma atenção especial por parte de poderes públicos sobre acesso e permanência do estudante da EJA na escola. Sobre essa questão inserida na contextualização histórica da EJA em Mato Grosso, Alves (1998, p.131) faz uma importante observação:

De forma concreta verificava-se pelos relatórios de diretores de Instrução Pública de Mato Grosso a frequência de operários e trabalhadores domésticos, domiciliados alguns a mais de 9 quilômetros da escola noturna de Cuiabá. Vários trabalhadores da zona rural se deslocavam até a escola impulsionados pela possibilidade de obterem melhores condições de vida.

Ou seja, devido às dificuldades de locomoção que possam existir para aqueles alunos jovens e adultos que moram distantes das escolas que frequentam, pode ocorrer desses estudantes deixarem de frequentarem as aulas, ocasionando na evasão escolar.

Vale ressaltar que a modalidade de Educação de Jovens e Adultos em todo o Estado de Mato Grosso está regulamentada através da Resolução n. ${ }^{\circ}$ 005/2011 do Conselho Estadual de Educação, que fixa as normas para a oferta dessa modalidade no Sistema Estadual de Ensino.

De acordo com o Plano Estadual de Educação de Mato Grosso, a população de jovens e adultos é caracterizada basicamente por dois grupos de faixas etárias: os de 15 a 24 anos, e os acima de 24 anos. Essa caracterização é importante para a elaboração da proposta pedagógica e planos de cursos destinados aos jovens e adultos. É a partir dessa perspectiva que as Orientações Curriculares para a Educação Básica nesse Estado (2010a; 2010b) no que concerne a parte específica da EJA foram elaboradas.

É necessário situar nessa discussão as Diretrizes Curriculares Nacionais para a Educação de Jovens e Adultos, instituídas pela Resolução CNE/CEB n. ${ }^{\circ}$ 1/2000. Destaca que as instituições de ensino que ofertarem cursos de EJA deverão seguir e atender obrigatoriamente essas Diretrizes. No entanto, essa Resolução assegura que a própria EJA tenha seu modelo pedagógico em consonância com as propostas pedagógicas das instituições de ensino que a ofertarem, considerando os perfis dos estudantes jovens e adultos e as suas faixas etárias, além de se basear em três princípios: o da equidade; da diferença; da proporcionalidade.

Sobre essas Diretrizes, Soares (2002) entende que essas surgiram num momento em que a necessidade de aprofundar nas discussões sobre essa modalidade educacional e seu público são necessários e relevantes para se entender como a EJA vem se configurando como política pública no Brasil nos últimos anos.

Assim, as Diretrizes vão pontuar que a EJA deve desempenhar três importantes funções: reparadora - no sentido de restaurar um direito a educação negada anteriormente aos jovens e adultos -, equalizadora - igualdade de oportunidades ao estudante da EJA, com os demais alunos da educação básica, como a inserção no mercado de trabalho e na vida social -, qualificadora - refere-se a uma educação contínua, para toda a vida.

Segundo Di Pierro (2010) é preciso entender a EJA como garantia do acesso da educação como direito de todos os cidadãos, pois, é necessário e urgente que não apenas a escola, mas o Estado possa oferecer condições plenas de acesso e permanência do sujeito jovem e adulto a uma educação de qualidade. Porém, para Machado (2007; 2009) a Educação de Jovens e Adultos ainda continua uma educação popular freireana, pelo fato de a educação ser uma importante ferramenta de transformação social, o que leva a se criar 
frequentemente novas estratégias para o fortalecimento e consolidação da EJA e, consequentemente, destacar a luta e o direito a educação não apenas como acesso a qualidade, mas o reconhecimento de jovens e adultos como importantes sujeitos da educação.

Nesse sentido, a conquista do direito a EJA vem sendo fortemente marcada pela intensa mobilização e expressão da sociedade civil frente ao poder público, tendo nos Fóruns de EJA regionais e estaduais seus principais movimentos de defesa e reconhecimento dessa modalidade para a educação brasileira nos dias atuais.

A demanda por EJA nunca é universal, considerado todos aqueles que não têm escolaridade em cada nível de ensino por várias razões: necessidade de trabalhar, subutilização da leitura e da escrita no cotidiano das suas vidas, ausência de motivação para o retorno a escola, dificuldades de acesso, entre outras (HADDAD, 2007, p.207).

É importante ressaltar que as reflexões históricas sobre a EJA têm no educador Paulo Freire sua principal referência, o qual propôs um modelo pedagógico baseado na alfabetização e conscientização crítica. Como exemplo, foi criado o Plano Nacional de Alfabetização baseado nos estudos desse teórico por todo o país, mas que foi interrompido pelo regime militar em 1964, sendo substituído pelo Movimento Brasileiro de Alfabetização - MOBRAL.

Nesse sentido, a contextualização histórica da Educação de Jovens e Adultos no Brasil e, especificamente, em Mato Grosso é necessária e relevante para entendermos o contexto o qual se insere o problema deste estudo, no campo da pesquisa em história da educação.

\section{Relações entre Arte e Sociedade}

A arte está presente na sociedade por meio de diferentes manifestações artísticas, como as tradicionais pinturas, desenhos e esculturas, além da música, dança, teatro e tantas outras. Arte é conhecimento, pois é uma área do saber. Estimula e desenvolve a percepção, a imaginação, a sensibilidade e a criatividade das pessoas. Desperta nelas variados sentimentos e emoções, ao produzir diferentes interpretações da obra/objeto artístico. Desde os primórdios da humanidade existe estreita relação entre arte e sociedade.

Sobre o significado da arte, Ferraz; Fusari (2010, p.101) esclarecem que como a arte está relacionada diretamente ao seu tempo histórico, devemos "aprofundar estudos, ampliar reflexões, que nos levem a compreensão da arte, com suas múltiplas formas, tanto dentro do nosso tempo, quanto em diferentes épocas". Ou seja, é preciso refletir sobre seus significados, sentidos e funções se quiser entendê-la no processo artístico, social e educativo.

A arte é uma das mais inquietantes e eloquentes produções do homem. Arte como técnica, lazer, derivativo existencial, processo intuitivo, genialidade, comunicação, expressão, são variantes do conhecimento arte que fazem parte de nosso universo conceitual, estreitamente ligado ao sentimento de humanidade (FERRAZ; FUSARI, 2010, p.101).

Refletir sobre essas dimensões oferece a oportunidade de ampliar a discussão sobre a arte na EJA, inseridas no bojo da história da educação. Desse modo, para entender 
como o homem concebe a sociedade em que vive, é preciso compreender como ele se relaciona socialmente e discute questões pertinentes aos campos da cultura, das tradições, dos valores, crenças e normas e, consequentemente, da arte, na sociedade da qual ele faz parte. Diante dessa premissa, o conhecimento é construído socialmente pelo ser humano por mediação da linguagem, a qual possibilitará sua socialização de modo a construir sua própria história.

A arte assume papel fundamental na sociedade, pois sendo linguagem é um instrumento com o qual o ser humano se comunica e representa de diversas maneiras a realidade a sua volta. A arte, manifestada de diferentes formas, será a expressão dessa realidade. Assim, toda obra, em especial a artística, expressa uma visão de mundo. Essa visão não envolve apenas as experiências e vivências que o indivíduo teve no passado ou tem no presente, mas também expressa perspectivas para o futuro, de acordo com as interpretações e percepções que esse sujeito tem da realidade.

À luz desse pensamento, a obra de arte possibilita ao jovem e o adulto da educação trazer o novo, que constitui seu modo de ver e conceber a realidade, assim como as transformações ocorridas na sociedade, ressaltando o processo criativo, original e individual da obra, que só ele é capaz de captar e materializar nela.

Essa apreensão da realidade por meio da arte e a construção de novas realidades leva o aluno da EJA a transformá-la e a humanizar-se dialeticamente. Ou seja, por meio da arte "os indivíduos podem apreender uma nova visão de mundo" (PEIXOTO, 2003, p.56). Com efeito, os alunos da Educação de Jovens e Adultos poderão ampliar sua consciência da realidade a qual estão inseridos como importantes sujeitos histórico-sociais.

Segundo Bourdieu (2004) todas as produções culturais presentes na sociedade são objetos de análise da ciência. Dentre essas, destaca-se a própria arte. A partir dessa reflexão, esse sociólogo elaborou a noção de campo que, aplicada à produção cultural, refere a um mundo social que produz, reproduz e dissemina a arte. Entendemos que é nesse mundo social que estão inseridas as instituições escolares e os alunos da EJA.

A noção de campo construída por esse intelectual é, ao mesmo tempo, um campo de forças e um campo de lutas. Ou seja, pode descrever as contradições sociais ou as relações de dominação existentes num determinado campo. Com efeito, a posição que os sujeitos sociais ocupam na estrutura social é que determinará suas decisões, e o que podem ou não fazer. Só é possível compreender a fala ou o fazer desse indivíduo inserido num campo se estiver em condições de relatar ou narrar a posição que ocupa nesse lócus.

A concepção colocada por Bourdieu pode ser aplicada à Educação de Jovens e Adultos, pois são sujeitos sociais que sofrem sérios problemas que afetam a sua permanência e continuidade nos estudos, ocasionando outros problemas como a evasão escolar. Estão inseridos num campo de lutas de classes, com forte desigualdade social. Daí, a importância de dar voz a esses sujeitos, de compreender suas falas nas entrevistas gravadas e transcritas realizadas no campo da pesquisa desta investigação, para que possam ter o direito de serem ouvidos numa sociedade cada vez mais excludente.

Bourdieu (2004) apresenta um argumento bastante interessante que nos faz pensarmos sobre a arte e o aluno da EJA: dependendo da formação social do estudante, ele pode conseguir apreender a informação proposta pela obra, decodificando-a, ou não. Essa capacidade de leitura, de compreensão da obra é limitada em cada indivíduo. Dessa forma, se as informações da obra ultrapassam a capacidade de compreensão desse indivíduo, ou seja, se a mensagem da obra excede a sua possibilidade de apreensão, ele passa a se desinteressar pela obra, devido a sua incapacidade de compreendê-la. 
É o que ocorre frequentemente com o jovem e o adulto da educação, que tem negado esse acesso à cultura artística presente na sociedade, tida como elitizada, para poucos. Ou seja, se o jovem e o adulto não consegue fazer a leitura de uma obra de arte, ele se distancia dela e, consequentemente, se afasta dos espaços culturais e artísticos como os museus e centros culturais, importantes para a sua formação estética e cultural.

A obra de arte considerada enquanto bem simbólico só existe enquanto tal para aquele que detém os meios para que dela se aproprie pela decifração, ou seja, para o detentor do código historicamente constituído e socialmente reconhecido como a condição da apropriação simbólica das obras de arte oferecidas a uma dada sociedade em um dado momento do tempo (BOURDIEU, 2004, p.283).

Na contemporaneidade a produção de obras artísticas e o seu consumo é restrita a alguns setores sociais. Nem toda obra produzida está acessível ao grande público, e mesmo quando isso acontece, pelo menos a maioria se encontra alienada pelos produtos da arte de massas, desprovendo-os de sensibilização estética. Esse fator também reforça a ideia de que a arte, de uma forma geral, é para uma classe socialmente privilegiada.

É importante ressaltarmos que o museu é um céu aberto a todos. Mas não são todos que frequentam esse espaço. As pessoas de classes sociais mais desfavorecidas não frequentam esses lugares porque não conseguem entender a obra de arte ali presente. Se sentem "fora do lugar". Na verdade, esses espaços são construídos para determinados segmentos da sociedade, para aqueles que têm conhecimento em arte, ou capital cultural na linguagem de Bourdieu, por isso, desse afastamento entre a arte e o estudante da Educação de Jovens e Adultos.

No que tange ao trabalho, por meio da arte o homem expressa seu lado criativo e expressivo. O pensador alemão Karl Marx (1818-1883) foi o primeiro a ver a relação entre arte e trabalho por meio da natureza criadora do homem. Para chegar a esse conceito, era preciso superar a concepção da arte e do trabalho como atividades opostas. Assim, arte e trabalho apresentam um fundamento comum: são manifestações criadoras do homem.

Quando o trabalho do artista deixa de expressar a essência humana, cai na utilidade meramente material. $\mathrm{O}$ artista deixa de produzir por uma necessidade interior, deixando de explicitar sua riqueza humana. Quando o artista cria, respondendo a essa necessidade interior subjetiva, ele cria um objeto artístico humanizador.

Marx afirmou que o nascimento da arte está diretamente relacionado à capacidade do homem de libertar a mão para produzir trabalho, iniciado no período pré-histórico. Desde os ancestrais a mão é o órgão do trabalho e o produto do trabalho e, que só depois dessa condição, é que foi possível produzir arte.

Desse modo e, por estar relacionado à natureza, o trabalho produzido modifica as formas naturais, segundo a vontade daquele que o produz, neste caso, o homem. Assim, Marx e Engels se expressam ao escrever sobre a origem da arte:

O nascimento da arte e da ciência só eram possíveis graças a uma divisão reforçada do trabalho entre as massas encarregadas do trabalho manual simples e alguns privilegiados entregues a direção do trabalho, ao comércio, aos assuntos do Estado e, mais tarde, as ocupações artísticas e científicas (MARX; ENGELS, 1974, p.56). 
Para Marx, a arte é um produto do trabalho humano da história e uma forma de expressão e conhecimento da realidade, no qual o homem, ao produzir arte, toma consciência das transformações sociais ocorridas na sociedade. As relações entre a arte e a sociedade passam a se intensificarem pelo fato da atividade artística se comunicar socialmente com os outros, levando o observador - não necessariamente o criador - a apreciar a experiência humana intencionada na obra do artista.

Nesse sentido, podemos afirmar que a natureza criadora do homem se encontra no trabalho, materializado na forma de objeto artístico.

\begin{abstract}
Quando o trabalho artístico se assemelha ao trabalho assalariado, quando a apreciação artística se converte em produção para o mercado (produção "produtiva", produção pela produção ou produção de mais-valia) e quando se valoriza a obra de arte não por seu valor específico, mas por seu valor de troca, econômico, isto é, quando se aplica a produção artística as leis da produção material capitalista, quando tudo isso ocorre, a arte é negada ou limitada, em sua estrutura interna própria, como manifestação da capacidade de criação do homem (VÁSQUEZ, 2011, p.194).
\end{abstract}

Ou seja, o capitalismo é hostil à arte na linguagem marxista. A contradição entre arte e capitalismo se manifesta quando o artista não encontra mais motivo artístico, negando sua obra à sociedade. Dessa forma, passará a ver essa realidade como hostil à arte, ao perceber seu trabalho se tornando mercadoria, objeto alienado.

$\mathrm{Na}$ medida em que se torna mercadoria, considerada como valor de troca, a obra de arte se desumaniza, perde sua qualidade e sua relação com o homem. Isso por que "o valor de troca de uma mercadoria, diferentemente do valor propriamente estético, não leva em conta as propriedades sensíveis, a forma do objeto" (VÁSQUEZ, 2011, p.183). Com efeito, o trabalho perde o seu lado criativo, pelas mãos do homem, e se afasta aos poucos da arte. Sendo criação, arte é trabalho e não deve ter sua liberdade de criação negada.

Ao limitar sua capacidade de criação, o artista deixa de expressar sua própria personalidade. Assim, concordamos com o autor ao afirmar que "a liberdade de criação, portanto, é uma condição necessária para que o artista possa explicitar sua personalidade" (VÁSQUEZ, 2011, p.197). O artista pode escapar dessa hostilização do capitalismo à arte criando segundo sua necessidade interna de expressão.

Podemos dizer, portanto, que a tese de Marx estabelece uma relação negativa entre arte e capitalismo. Ao afirmar que a produção capitalista é contrária a arte, Marx diz que é preciso considerar o contexto histórico da obra, isto é, levar em consideração a obra em seu tempo. A obra de arte é entendida, então, como mercadoria de troca na sociedade capitalista.

\title{
Funções Sociais da Arte
}

A arte é criação, é invenção. Está diretamente relacionada à produção essencialmente humana. Ao longo da história a arte desempenhou diferentes funções, o que possibilitou a construção de diferentes linguagens, novos olhares e interpretações, produzindo novos sentidos. Em determinadas épocas, a arte assumiu funções definidas pela própria sociedade a qual estava inserida. As influências sociais, econômicas, políticas e tecnológicas contribuíram para que as obras de arte pudessem assumir diferentes finalidades ao longo do tempo histórico. 
Como menciona Vásquez (2011) a decoração, considerada uma das funções da arte, está presente na sociedade deste a arte rupestre, quando o homem pré-histórico criou e transformou instrumentos conduzindo-os temas decorativos, como, por exemplo, ao criar linhas nas figuras que ele desenhava ou pintava nas paredes das cavernas.

Essas decorações em objetos se modificaram quando o homem pré-histórico criou imagens figurativas, como animais, com um grau mais avançado da representação do real, com certos realismos nas imagens. Contudo, Vásquez (2011) chama a atenção pelo fato de que o homem só chegou a esse processo devido ao trabalho humano, que ultrapassou o objeto meramente utilitário, ao incorporar novas formas geométricas e figurativas à arte rupestre.

Pedrosa (1995) considera que essa função decorativa tinha mais uma marca de símbolo do que estético para os povos primitivos. Na medida em que a sociedade evoluiu, esse motivo decorativo passou a se referir não apenas a animais caçados, mas também a paisagens naturais, o que proporcionou o desenvolvimento estético.

Segundo Peixoto (2003) nos povos primitivos a arte estava relacionada à prática de rituais, a qual tinha a função de se integrar totalmente na vida desses povos. Arte, então, tinha uma função ritualística, mágica. Nas civilizações antigas foi possível perceber algumas diferenciações na expressão artística: no Egito havia os artesãos populares e os artesãos da corte; na Grécia antiga, as artes manuais como a pintura e escultura não tinham o mesmo privilégio da poesia, do teatro e da música; na Roma antiga, era comum se colecionar entre as famílias nobres obras de arte. Para essa teórica, talvez tenha sido a primeira tentativa de se estabelecer uma relação entre artista, obra de arte e público.

Durante a Idade Média o "cliente" não era o Estado, mas sim a Igreja. Se na Grécia antiga a arte tinha função política, com a Igreja na Idade Média a arte assumiu função política e religiosa, como meio de disseminação da consciência católica imposta pela Igreja. O culto às imagens nesse período foi grande, pois o conteúdo religioso era acentuado nas iconografias, o que levou a Igreja a ser reconhecida como instrumento de educação, época em que havia inúmeras pessoas que não sabiam ler nem escrever, visto que "uma pessoa ilustrada podia evocar a realidade significada pela imagem, sem necessidade de saber ler" (VÁSQUEZ, 2011, p.159).

Entretanto, alfabetizar visualmente as pessoas não significou que as mesmas pudessem saber ler e entender com propriedade uma obra de arte. Nesse sentido, a arte era considerada uma forma de instrução - função educativa. Essa função tinha conteúdo religioso segundo os interesses da Igreja - consumidor - e não do artista. A arte dessa época era utilizada no sentido pedagógico e religioso, e não material. Vásquez assim analisa as condições em que se dá trabalho artístico, na relação artista versus igreja:

O artista cria para satisfazer a encomenda do consumidor, a Igreja. E, dado que a principal finalidade da obra é pedagógica, o artista se sujeita as prescrições da Igreja, que fixa os temas, a fim, de que a pintura seja de acordo com a sua função pedagógica - uma espécie de escrita em imagens. Contudo, em que pese essa função educativa, a arte se mantém submetida ao conteúdo ideológico que lhe imprime a religião e que fixa sua atitude diante da realidade, a qual não é vista pelo artista em si, mas como anexo resplendor ou alegria de uma realidade que a transcende (VÁSQUEZ, 2011, p.160).

A função naturalista da arte, bastante pontuada a partir da segunda metade do século XIX, tendo na fotografia sua principal mediadora, era voltada para a representação 
fiel da realidade, tanto do homem quanto do objeto. Já a função formalista se refere à forma com que a obra de arte se apresenta por meio de suas diferentes linguagens (DALMASO, 2011).

Dalmaso (2011) destaca ainda que no século XX a arte passou a ter uma função social voltada para os problemas econômicos e políticos presentes na sociedade, o que ficou mais evidente no final desse século através da diversidade de linguagens artísticas contemporâneas, destacando artistas como Cândido Portinari (1903-1962), Tarsila do Amaral (1886-1973) e artistas mais contemporâneos como o brasileiro Vik Muniz. Assim Vásquez concebe que:

Ainda que o objeto artístico possa cumprir - e tem cumprido ao longo da história da arte - as mais diversas funções (ideológica, educativa, social, expressiva, cognoscitiva, decorativa etc.), qualquer que seja a sua referência a uma realidade exterior ou interior já existente, a obra artística é, antes de mais nada, uma criação do homem, uma nova realidade. A função essencial da arte é ampliar e enriquecer, com suas criações, a realidade já humanizada pelo trabalho humano (VÁSQUEZ, 2011, p.42).

Nessas reflexões sobre as diversas funções da arte assumidas ao longo dos tempos, Vásquez faz uma interessante observação: para se produzir objetos de arte é necessário o aumento da produtividade do trabalho humano, que ultrapasse o consumo, para que o objeto supere a função utilitária, cumprindo a sua função estética. Ou seja, como condição necessária do aparecimento da arte é preciso que os objetos se libertem dessa função prática, utilitária, isto é, "para que um objeto se ajustasse a ela, era preciso que o material sofresse uma série de transformações até receber a estrutura mais adequada, isto é, a forma exigida pela finalidade ou função que o objeto devia cumprir" (VÁSQUEZ, 2011, p.65).

Com efeito, a descoberta pelo homem das finalidades de cada objeto na produção foi fundamental para o processo da passagem do trabalho à arte e, consequentemente, para o desenvolvimento de outras linguagens artísticas na sociedade contemporânea. A temática da função da arte também é mencionada pelos Parâmetros Curriculares Nacionais ao descreverem:

Uma função igualmente importante do ensino da arte tem a cumprir diz respeito à dimensão social das manifestações artísticas. A arte de cada cultura revela o modo de perceber, sentir e articular significados e valores que governam os diferentes tipos de relações entre os indivíduos na sociedade (BRASIL, 1997, p.19).

Assim, ao produzir arte, o estudante da EJA abre caminhos para se comunicar com as pessoas, ao expressar suas percepções, seu senso crítico, além de suas emoções, angústias, alegrias e anseios, exercendo o seu processo criativo, ao dialogar com o mundo social a sua volta, na produção de interpretações significativas da realidade.

Mesmo fazendo parte de um povo marcado historicamente por graves desigualdades sociais, a arte, enquanto criação essencialmente humana, portanto, humanizadora, pode levá-los a construir uma sociedade mais pensante, igualitária e democrática.

Nesse sentido, podemos afirmar que há um distanciamento entre a arte, tida na sociedade como conhecimento das elites e o estudante da Educação de Jovens e Adultos. É 
um problema histórico e se faz presente até os dias atuais. Ainda vigora na sociedade a concepção de que a arte é para a minoria, ou seja, para uma elite hegemônica. Essa denominação afasta a arte do grande público, o qual está inserido os estudantes da EJA, negando a eles o direito de conhecer e ter contato efetivo com as diversas manifestações artísticas e culturais, fundamentais para o desenvolvimento de seu senso crítico e estético.

\section{Conceitos de Arte na EJA}

A intenção não é identificar o perfil dos estudantes entrevistados, mas buscar ampliar estudos e pesquisas sobre a arte na EJA no campo da pesquisa em história da educação. Nesse sentido, as entrevistas realizadas com esses sujeitos da pesquisa possibilitaram constatar uma concepção de arte voltada para a "função decorativa", bastante presente na arte para a maioria desses alunos, e como "totalidade" na vida deles, quando opinaram o que é arte:

Arte é tudo aquilo que a gente faz. Você vai fazer o que, uma comida, vai fazer o que... outra coisa que a gente faz com carinho, acho que é uma arte. (C3)

Arte é tudo que está em minha volta, é tudo que está presente, tudo... Tudo pra mim é arte! (HI)

Tudo... Tudo no nosso dia a dia é arte. (V5)

Arte é... Tudo que tá a nossa volta. Tudo que a gente faz é arte. (J9)

Arte pra mim é tudo... No caso os pássaros, as nuvens... O movimento da folha, uma fotografia... a televisão em si...tudo, tudo! (J9)

Praticamente tudo, porque ao redor pra mim é arte. Então, tudo que você vê é bonito, é belo. Você tem que tentar decifrar o que é arte, então, é bem bonito! (E1)

Arte... É tudo que acompanha nossa vida, por exemplo, uma casa é uma arte porque na casa você precisa de muita coisa pra decorar. Arte é também um monte de fruta que eles decoraram na porta do refeitório. (R6)

Tudo, porque arte é você arrumar, é uma coisa bonita, aí pra você arrumar precisa de criatividade. Arte é cinema, tá no dia a dia... tá nas ruas, tá em tudo. (J6)

Arte pra mim é como beleza... É passar pra nós, decifrar pra nós... Arte pra mim é isso, beleza, humanidade. (E1)

É recorrente na fala da maioria dos alunos da EJA que arte é decoração. Na verdade, a arte como decoração está presente na sociedade desde sempre. Está em 
praticamente todos os lugares. É uma dimensão estética que acompanha a transformação da humanidade, pois as pessoas sempre buscam o belo em suas vidas: desde comprar uma escultura e pintura para enfeitar a sua casa, até a forma de se vestir uma roupa. E diante disso, o conhecimento de arte também está presente.

\begin{abstract}
Ainda que o objeto artístico possa cumprir - e tem cumprido ao longo da história da arte - as mais diversas funções (ideológica, educativa, social, expressiva, cognoscitiva, decorativa, etc.), somente pode cumprir essas funções como objeto criado pelo homem. Qualquer que seja a sua referência a uma realidade exterior ou interior já existente, a obra artística é antes de mais nada, uma criação do homem, uma nova realidade. A função essencial da arte é ampliar e enriquecer, com suas criações, a realidade já humanizada pelo trabalho humano (VÁSQUEZ, 2011, p.42).
\end{abstract}

Nesse sentido, podemos afirmar que a função decorativa se disseminou na medida em que a arte e a sociedade se evoluíram ao longo da história para atender as necessidades humanas. Contudo, essas reflexões permitem dizer que conceituar arte não é tarefa fácil.

Para Ferraz; Fusari (2010) não é fácil definir o conceito de arte, pois, ao longo da história diversas teorias surgiram na tentativa de propor interpretações sobre seu significado, a saber: arte como linguagem, como técnica, como comunicação, expressão, lazer, criação etc. Sobre esse assunto, as autoras afirmam:

Para nós a concepção de arte que pode auxiliar na fundamentação de uma proposta de ensino e aprendizagem artísticos, estéticos, e atende a essa mobilidade conceitual, é a que aponta para uma articulação do fazer, do representar e do exprimir (FERRAZ; FUSARI, 2010, p.20).

Seus depoimentos também evidenciam que a arte é tudo, pois a arte na visão desses estudantes tem serventia para alguma coisa. Quando os alunos de EJA falam que "arte é tudo", não é do senso comum, é um conhecimento que foi construído por meio de suas experiências acumuladas ao longo de suas vidas.

A arte está em todos os lugares. Ela não surgiu por acaso. Ao contrário: surgiu na sociedade devido a uma necessidade humana de transformar a natureza. Para tudo que se precisa fazer precisa de conhecimento. Portanto, arte é conhecimento. Presente na sociedade, manifestada de diferentes formas e encontrada em diversos lugares, conceber a arte apenas como produto utilitário é deixar de lado o conhecimento produzido, o aprendizado e o legado cultural e artístico que a arte pode oferecer.

Esse "tudo" que os alunos consideram a arte está relacionado somente ao que é belo, ao que gostam ou gostariam de ver numa obra de arte, ou seja, se arte para eles é tudo, é porque as coisas ou objetos presentes no dia a dia, os quais julgam serem bonitos ou agradáveis, são formas de arte para eles. Por isso que a maioria dos discentes entrevistados a concebem como decoração.

Entretanto, para Read (1987, p.21) nem sempre arte é aquilo que é belo, pois a arte não é necessariamente beleza. Muitas vezes, ao se falar em arte, é retomada a questão que envolve a beleza de uma obra de arte. $\mathrm{Na}$ verdade, os conceitos de Arte e Belo assumiram, ao longo da história, diversos sentidos e significados de acordo com as normas de cada época em que foi criada e disseminada, ou seja, o que era belo no renascimento do século XV pode não ser belo nos dias atuais. 


\section{A Formação Escolar do Aluno da EJA em Mato Grosso}

São apresentadas nessa parte do artigo discussões sobre alguns aspectos da formação escolar do estudante da EJA, na intenção de entendermos como ocorreu a sua escolarização em Mato Grosso. Logo, o espaço escolar é um importante lugar que pode oferecer possibilidades de produção artística no convívio com diferentes linguagens. É na escola que a arte pode se tornar acessível aos estudantes, ou seja, é neste espaço que,

se poderia exercer o princípio democrático de acesso à informação e formação estética de todas as classes sociais, propiciando-se na multiculturalidade brasileira uma aproximação de códigos culturais de diferentes grupos (BARBOSA, 2012, p.34).

Mas, é necessário que o professor e a própria escola ofereçam condições efetivas de acesso contínuo e permanência do estudante da EJA à educação. Assim, com relação aos sujeitos jovens e adultos quando perguntados qual a série ou ano em que interromperam os estudos, responderam:

Primeiro ano. Foi em 2010. (C3)

Eu parei mesmo assim no terceiro ano, aí fiquei mais ou menos 3, 4 anos sem estudar no segundo grau. Se eu não me engano, foi em 2006... 2007, por aí. Voltei ano passado. (E1)

Segundo ano do ensino médio... em 2011. (J6)

Foi no... segundo grau. Foi em 1999. (J2)

Eu parei na metade do segundo... ano retrasado, em 2010. (L5)

Foi no primeiro ano... ensino médio...em 2008...2009...e voltei em 2010. (M1)

Parei no terceiro ano, em 2006. Voltei agora, esse ano. (R3)

No primeiro do ensino médio. Em 2009. Voltei em 2011. (R6)

Eu parei no segundo ano, em 2011. (T4)

Segundo ano do ensino médio. Voltei no meio do ano de 2010, aí fiquei no ano de 2011 parada e voltei esse ano (2012). (V5)

De acordo com suas falas a grande maioria interrompeu seus estudos ainda no ensino médio. Essa questão da evasão escolar é um grave problema que já perdura nas escolas brasileiras há muitos anos. No que toca a Educação de Jovens e Adultos, muitos alunos deixam de frequentar a escola para trabalhar, ajudar a família, entre outros tantos motivos. Tiveram sua escolarização interrompida ou negada por circunstâncias diversas. Geralmente, são pessoas com baixa renda e com o objetivo de conseguir uma melhor 
inserção no mercado de trabalho, o que implica numa volta a escola para que possam, então, concluir os estudos.

Nesse sentido, pensamos que o Estado tem a obrigação de oferecer educação com qualidade, sendo necessário haver uma consonância e cooperação entre o poder público e demais órgãos das esferas municipais, estaduais e federal para esse acesso, permanência e continuidade dos estudos do jovem e adulto da educação.

Além disso, apenas quatro relataram que interromperam seus estudos ainda no ensino fundamental:

Eu parei na quinta série, há 30 anos atrás...em 1983. Voltei em 2010. (J2)

Eu tava na segunda série do primário, eu tava com 10 anos, aí eu voltei a estudar quando eu tava com 28. 18 anos eu fiquei sem estudar...voltei em 2009. (L9)

Em 1984. Não terminei a quinta série. Voltei em 2008, há quatro anos. É muito bom, a mente da gente muda, aquela ansiedade que a gente tem acaba, só participando mesmo pra gente ver. (O9)

Há 18 anos. Então, acho que foi em 92 pra 93. (S2)

A partir dessa reflexão, defendemos a necessidade de uma formação pedagógica que se relacione com as experiências e vivências com os sujeitos jovens e adultos da educação, e com práticas e conteúdos pedagógicos que atendam as especificidades da EJA, de caráter multicultural e interdisciplinar, tendo na arte importante contribuidora e mediadora para que esse processo ocorra da melhor maneira possível, ao possibilitar experiências significativas durante os processos de ensino e aprendizagem a partir do contato contínuo com a arte.

Com a intenção de ampliar a compreensão da formação escolar do jovem e adulto da educação, foi perguntado a esses estudantes quais seriam as maiores dificuldades para estudar, e eles opinaram:

A dificuldade... Acordar cedo... Eu durmo muito tarde... Eu durmo às vezes uma hora da manhã, duas horas, aí eu tenho que acordar seis horas pra vir pra aula... porque eu trabalho. (C3)

Pra estudar? Acordar cedo. Eu trabalho até 10 horas da noite, por isso que fica difícil eu acordar cedo. (J9)

Trabalho... Associar essas duas coisas, até porque eu estudo o dia inteiro, estudo à tarde também, então, associar estudo com trabalho é um pouco difícil. (K8)

É que trabalho a noite... É muito cansaço, muito sono... Quem trabalha a noite o rendimento na sala de aula é pouco. (R6) 
Porque a gente tem que auxiliar casa, a família, os estudos, e o trabalho também... É meio complicado, mas a gente dá um jeito. $(S 2)$

\section{O trabalho. (T4)}

É unânime em suas falas a maior dificuldade que encontram ao irem para a escola: o trabalho. A maioria trabalha e tenta conciliar o estudo com a escola e com a família, que nem sempre, conseguem realiza-lo plenamente. Dessa forma, é importante ressaltarmos que,

os alunos da EJA são jovens e adultos, muitos deles trabalhadores, maduros, com larga experiência profissional ou com expectativa de (re) inserção no mercado de trabalho e com um olhar diferenciado sobre as coisas da existência. Para eles, foi à ausência de uma escola ou a evasão da mesma que os dirigiu para um retorno nem sempre tardio a busca do direito ao saber (BRASIL, MEC., 2000, p.34).

O aluno da EJA tem sua peculiaridade e corresponde a uma realidade, apresenta uma experiência de vida, pois são pessoas adultas que vivem no mundo do trabalho, com anseios e esperanças de uma vida melhor, mas também com "responsabilidades econômicas e familiares, com princípios éticos e morais formados a partir da experiência, do ambiente, da realidade cultural em que estão inseridos" (ALVARES, 2012, p.75). Portanto, veem no trabalho a perspectiva de emancipação de que tanto precisam para as suas vidas. Alvares (2012, pp.21-22) assim identifica o jovem e adulto que frequenta a escola:

O aluno adulto é um sujeito pleno de experiências vividas, que podem ser consideradas a porta de entrada para o conhecimento escolar. É no encontro entre os conhecimentos prévios e os conhecimentos escolares, na relação de troca entre os saberes do educando e os saberes do educador, que ocorrem mudanças significativas nos olhares, tanto do aluno quando do professor.

$\mathrm{Na}$ sequência das entrevistas, perguntamos aos estudantes se utilizam algum conhecimento em arte aprendido na escola em suas profissões, a minoria respondeu que sim:

Com certeza. Porque quando a gente é taxista, se propõe a ser taxista, a gente tem que ter um pouco de conhecimento geral e, quando um cliente embarca no táxi, geralmente ele quer conhecer a cidade onde que a gente mora, e pra isso a gente tem que ter conhecimento da arte religiosa, entendeu, das esculturas que existe... Tem uma arte aqui, por exemplo, que tem na frente da igreja... Da igreja não, da câmara municipal que é o marco centro geodésica da América do Sul. Este é sempre procurado por pessoas que vem de outros estados, de outras cidades, que eles querem saber onde é que fica esse marco, e é uma obra de arte. (O9) 
Sim. Eu trabalho... Eu trabalho como músico, toco durante a noite. (R3)

Tudo... tudo mesmo... pra eu criar um cabelo... Eu trabalho com isso, eu crio alguma coisa no cabelo de alguém... por isso é muito importante na minha vida a arte. (K8)

Segundo as análises feitas, verificamos que os alunos O9 e R3 ressaltam que utilizam em suas profissões - taxista e músico, respectivamente - algum conhecimento em arte. No caso do aluno $\mathrm{O} 9$, ele o utiliza como fonte de informação para o turista ou passageiro que ele leva em seu carro. Ao atuar como taxista, o aluno O9 informa aos passageiros - clientes - sobre os principais pontos turísticos da cidade, destes, alguns culturais e artísticos ressaltados em sua fala, como o centro geodésico da América do Sul, localizado no centro da cidade de Cuiabá, igrejas históricas dos séculos XVIII e XIX. O fato de ser taxista e ter conhecimento de vários lugares da cidade possibilita a ele disseminar esse conhecimento em arte a outras pessoas que até então desconhecem a cultura local.

No entanto, o depoimento da aluna K8, que trabalha como cabeleireira, nos chamou bastante a atenção. Ela relaciona o conhecimento em arte que ela aprendeu na escola com a sua profissão de cabeleireira, pois segundo ela, ela utiliza da criatividade para fazer diferentes cortes e tipos de cabelo em seus clientes, por isso, concebe essa "criação" como um conhecimento em arte que ela aprendeu na escola.

Essa relação entre trabalho e criação é ressaltada por Marx ao afirmar que o trabalho tem um caráter criador, ou seja, o homem produz objetos os quais se objetiva e expressa suas ideias e sentimentos. Desse modo, tanto a arte como o trabalho são criações de uma realidade que atende as necessidades humanas, assim como a obra de arte atende as necessidades internas de criação do artista e o trabalho atende as necessidades de sobrevivência do indivíduo.

Superar a diferença entre arte e trabalho é evidenciar sua capacidade criadora, uma nova realidade criada pelo homem. Pois "a obra de arte cria um público sensível à arte e capaz de sentir prazer com a beleza. Por conseguinte, a produção não cria apenas um objeto para o sujeito, mas também um sujeito para o objeto" (MARX; ENGELS, 1974, p.60).

Nesse raciocínio, os Parâmetros Curriculares Nacionais (BRASIL, 1997, p.19) complementam a reflexão da relação entre arte e trabalho:

A arte também está presente na sociedade em profissões que são exercidas nos mais diferentes ramos de atividades; o conhecimento em artes é necessário no mundo do trabalho e faz parte do desenvolvimento profissional dos cidadãos.

Por isso, trabalho e arte se assemelham, pois concebida como trabalho criativo a arte pode humanizar o jovem e o adulto da educação escolar, levando-o a construir sentidos para a sua vida, visto que o estudante de EJA é um ser pensante, histórico e social. A arte como criação essencialmente humana produz novos significados e interpretações da realidade através do fazer artístico, ao socializar diferentes visões de mundo. Talvez por isso, a aluna K8 tenha concebido a criação durante seu trabalho como conhecimento em arte aprendido na escola. 
A arte é trabalho, mas um trabalho verdadeiramente criador, na medida em que a capacidade de humanizar os objetos, de objetivação do homem neles, não tropeça com as limitações impostas no trabalho habitual por sua função utilitária. Sua utilidade é fundamentalmente espiritual; satisfaz a necessidade do homem de humanizar o mundo que lhe rodeia e de enriquecer com o objeto criado sua capacidade de comunicação. Nesse sentido, a arte é superior ao trabalho. O homem sente a necessidade de uma afirmação objetiva de si mesmo que só pode encontrar na arte (VÁSQUEZ, 2011, p.173).

Ao modificar o meio natural por intermédio do trabalho, o indivíduo humaniza a natureza, pois, o trabalho não é apenas criação de objetos que atendam às necessidades do homem, mas também, objetivação de ideias, expressões e sentimentos humanos.

$\mathrm{Na}$ intenção de identificar a presença da leitura na vida desses estudantes, perguntamos a turma da EJA se gostavam de ler e assim se posicionaram:

Eu gosto de ler jornal, revista. (C3)

Eu gosto de ler livro. (E1)

Eu gosto de ler literaturas, praticamente eu gosto de ler todas, mas sempre a gente se identifica com uma... Eu gosto mais de romance. $(J 2)$

Gosto de ler bastante jornal, revista... Eu gosto de me informar também. Há poucos tempos atrás, eu li a vida de Santos Dumont... Achei muito interessante. (O9)

Romance... Também de fatos que aconteceu. (R6)

Gosto. Livrinhos de poesia. (R9)

Eu gosto de ler. Eu pego os livros básicos de historinhas em quadrinhos. (T4)

A maioria respondeu que gosta de ler revistas e jornais, ora como lazer, ora como forma de buscar conhecimento. É possível perceber que a leitura está presente em suas vidas, por diferentes meios.

No entanto, isso nos chamou atenção, pois, durante as aulas observadas com a turma da EJA na pesquisa de campo, constatamos que os estudantes não realizavam leituras em sala de aula com frequência, pois a professora da disciplina de Arte trabalhava textos escritos com esses discentes, mas sem pedir para que os mesmos realizassem as leituras nessas aulas.

Partindo do princípio freireano de que a leitura é um ato de apropriação do conhecimento na interação do sujeito com o mundo, com seu meio social e cultural, por conseguinte a leitura e a interpretação de uma produção do campo da arte é também um processo de construção de sentidos para os sujeitos que a leem (COUTINHO, 2009, p.175). 
Sobre essa reflexão, é necessário esclarecer que a leitura verbal e visual possibilita ao estudante novas produções de significados em relação ao meio social o qual se encontra. Com efeito, ao considerar a leitura como uma leitura crítica do mundo, conscientizadora, como defendeu o pensador Paulo Freire, o jovem e adulto da EJA se tornará um sujeito mais ativo, crítico e participativo no contexto social e político o qual está inserido.

Em adição a essas análises, identificamos alguns alunos que gostam de ler assuntos relacionados à religião.

Gosto. Mais espírita. (K8)

Eu gosto mais de ler a Bíblia... Livros evangélicos. (L9)

Eu gosto de livro evangélico, eu leio bastante. (M4)

A Bíblia. (V5)

Ler é produzir sentidos por meio de textos verbais e visuais. Daí a importância das linguagens artísticas para a elaboração de textos ao trabalhar com jovens e adultos, pois poderão ter a oportunidade de elevar a sua capacidade de expressão verbal e visual. Ao ter contato com a linguagem artística o estudante da EJA poderá ampliar o seu universo de leitura e, consequentemente, a sua capacidade de compreensão de mundo. Aprenderá leituras visuais e não apenas a escrita tradicional, que o levará a construir novos significados da realidade a sua volta e a produzir textos significativos, pois "diante do mundo, o homem estabelece uma relação sujeito-objeto da qual nasce o conhecimento, que ele expressa por uma linguagem" (FREIRE, 1979, p.38).

\section{Palavras Finais}

É evidente nas falas dos alunos da EJA que a maioria deixou a escola devido à necessidade de trabalhar, ocasionando a evasão escolar, que é um grave problema para a educação brasileira. Nas próprias aulas de Arte observadas no campo da pesquisa pudemos constatar alguns alunos que deixaram de frequentar as aulas no início da disciplina, enquanto outros começaram a frequentar as aulas já quase no fim do ano letivo.

Ao longo da história social se criou uma arte tão elevada, que ela se tornou inacessível para a maioria da população, inclusive para os jovens e adultos da educação escolar, que tem também o direito de acessar e frequentar espaços culturais e artísticos. A arte é consumida por determinados segmentos sociais, que vai contribuir para $\mathrm{o}$ distanciamento da arte com o estudante da EJA.

Por meio das obras de arte é possível conhecer como as pessoas de determinado período histórico retratadas numa pintura, por exemplo, viviam através de suas vestimentas e outros elementos visuais presentes numa pintura que possam identificar determinadas épocas históricas. Ou seja, ela mostra os padrões estéticos de uma sociedade e torna possível a reflexão sobre eles. A arte possibilita um leque amplo de produção de conhecimento histórico.

Logo, a arte assumiu diferentes funções ao longo da história principalmente devido ao contexto social e político da época em que foi produzida e disseminada. Algumas dessas funções, como a decorativa, ainda é bastante presente em trabalhos 
artísticos contemporâneos e, também, em algumas concepções de alunos da EJA, por estarem presentes em suas vidas por diferentes meios.

É preciso esclarecer que os estudantes da EJA não são crianças! Não agem, não pensam e não aprendem como crianças! Devido à bagagem significativa que trazem de suas experiências de vida é importante o professor adotar metodologias que possam atender suas reais necessidades de aprendizagem. Diante disso, pensamos que a experiência estética pode contribuir relevantemente para o seu processo de ensino e aprendizagem escolar.

Na EJA em Mato Grosso, as concepções dessa modalidade de ensino se modificaram com o tempo. Em relação à carga horária estabelecida em Lei, a mesma foi fixada em quatro horas de aula, o que torna desgastante para aquele jovem e adulto que, em sua maioria, trabalha em média oito horas por dia e em condições geralmente precárias de trabalho.

A Educação de Jovens e Adultos estabelecida pelo Plano Estadual de Educação em Mato Grosso busca contemplar os mesmos objetivos propostos pelo Conselho Nacional de Educação como, por exemplo, a elevação do nível de escolaridade de jovens e adultos; diminuir as desigualdades sociais e regionais e melhorar a qualidade da educação oferecida a esses estudantes. Ou seja, podemos afirmar que há uma consonância, pelo menos teórica, entre esses documentos oficiais, no que toca aos pressupostos e dispositivos legais sobre a regularização da EJA no país e na educação mato-grossense.

Podemos dizer, portanto, que para alguns alunos jovens e adultos a arte pode estar na pintura que viram moldada em um quadro, no desenho feito na escola ou, mesmo, na música que gostam de ouvir. Para outros a arte pode não ter significado algum ou não tenha grande importância. Porém, ela pode significar muito e ter importante papel na vida do estudante da EJA ao transmitir valores, culturas e construir conhecimentos necessários para a sua formação contínua enquanto cidadão. Pode possibilitar ao aluno uma experiência estética significativa, que poderá acompanha-lo por toda a vida.

\section{Referências}

ALVARES, S. C. Educação Estética na EJA: a beleza de ensinar e aprender com jovens e adultos. São Paulo: Cortez, 2012.

ALVES, L. M. Nas trilhas do ensino: educação em Mato Grosso 1910 - 1946. Cuiabá: EdUFMT, 1998.

BARBOSA, A. M. A imagem no ensino da arte: anos 1980 e novos tempos. 8.ed. São Paulo: Perspectiva, 2012.

BOURDIEU, P. A economia das trocas simbólicas. 5.ed. São Paulo: Perspectiva, 2004.

BRASIL. MEC. Parecer CNE/CEB n. 11 de maio de 2000. Brasília: MEC, 2000.

BRASIL. Parâmetros Curriculares Nacionais: Arte. Brasília: MEC/SEF, 1997. 
COUTINHO, R. G. Estratégias de mediação e a abordagem triangular. In: BARBOSA, Ana Mae (Org.). Arte/educação contemporânea: consonâncias internacionais. 3.ed. São Paulo: Cortez, p.171-185, 2009.

DALMASO, E. M. Ensino da Arte sob a ótica de professoras e alunos do ensino médio. 171f. Dissertação (Mestrado em Educação). Universidade Federal de Mato Grosso, Cuiabá, 2011.

DI PIERRO, M. C. A Educação de Jovens e Adultos no Plano Nacional de Educação: avaliação, desafios e perspectivas. Educ. Soc., Campinas, v.31, n.112, p.939-959, jul./set. 2010. Disponível em: < http://www.scielo.br/pdf/es/v31n112/15.pdf >. Acesso em 13 fev. 2014.

FERRAZ, M. H.; FUSARI, M. F. Arte na educação escolar. 4. ed. São Paulo: Cortez, 2010.

FREIRE, P. Educação e mudança. Rio de Janeiro: Paz e Terra, 1979.

HADDAD, S. A ação de governos locais na educação de jovens e adultos. Revista Brasileira de Educação, v.12, n.35, p.197-211, maio/ago. 2007. Disponível em: < http://www.scielo.br/pdf/rbedu/v12n35/a02v1235.pdf>. Acesso em 15 fev. 2014.

MACHADO, M. M. A educação de jovens e adultos no Brasil pós-Lei no 9.394/96: a possibilidade de constituir-se como política pública. Em Aberto, Brasília: INEP. v.22, n.82, p.17-39, 2009. Disponível em: <

http://emaberto.inep.gov.br/index.php/emaberto/article/viewFile/1576/1268>. Acesso em 16 fev. 2014.

- A atualidade do pensamento de Paulo Freire e as políticas de educação de jovens e adultos. Revista REVEJA, v.1, n.1, dez. p.20-33, 2007.

MATO GROSSO. Orientações Curriculares: Concepções para a Educação Básica. Secretaria de Estado de Educação de Mato Grosso. Cuiabá: Defanti, 2010a.

Orientações Curriculares: área de linguagens: educação básica.

Secretaria de Estado de Educação de Mato Grosso. Cuiabá: Defanti, 2010 b.

MARX, K.; ENGELS, F. Sobre literatura e arte. 4.ed. Lisboa: Editorial Estampa, 1974.

PAIVA, V. História da educação popular no Brasil: educação popular e educação de adultos. 6.ed. São Paulo: Loyola, 2003.

PEIXOTO, M. I. Arte e grande público: a distância a ser extinta. Campinas, SP: Autores Associados, 2003.

PEDROSA, M. Política das artes. São Paulo: Editora USP, 1995. 
PLANO ESTADUAL DE EDUCAÇÃO. Fórum Estadual de Educação (2006-2016). Cuiabá: Secretaria Estadual de Educação de Mato Grosso/SEDUC/Assembleia Legislativa/SINTEP/UNDIME/AME. 2006.

READ, H. O sentido da arte. 6.ed. São Paulo: Ibrasa: Instituição Brasileira de Difusão Cultural, 1987.

RESOLUÇÃO NORMATIVA CEE/MT n. ${ }^{\circ} 005 / 2011$. Fixa as normas para a oferta da educação básica na modalidade de Educação de Jovens e Adultos no Estado de Mato Grosso. Cuiabá: Conselho Estadual de Educação-CEE/Secretaria Estadual de EducaçãoSEDUC, 2011.

REZENDE, M. A. Os saberes dos professores da Educação de Jovens e Adultos: o percurso de uma professora. Dourados, MS: Editora da UFGD, 2008.

SÁ, E. F; SOUSA, E. J. A escolarização de jovens e adultos em Mato Grosso (1872-1927). Educação e Fronteiras On-Line, v.2, n.4, jan./abr. p.97-109, 2012. Disponível em: http://www.periodicos.ufgd.edu.br/index.php/educacao/article/view/1560/pdf_113. Acesso em 16 fev. 2014.

SOUZA, A. P. Alfabetização de jovens e adultos em Mato Grosso: uma leitura das campanhas oficiais de 1947. 162f. Dissertação (Mestrado em Educação). Universidade Federal de Mato Grosso, Cuiabá, 2007.

VÁSQUEZ, A. S. As ideias estéticas de Marx. Tradução de Carlos Nelson Coutinho. 3.ed. São Paulo: Expressão Popular, 2011.

\footnotetext{
${ }^{1}$ Mestre em Educação pela UFMT. Universidade Federal de Mato Grosso.

${ }^{2}$ Doutora em Educação pela UNESP. Universidade Federal de Mato Grosso.

Recebido: março-14 Aprovado: julho-15
} 